\title{
Health Promoting and Lifestyle Behaviour Changes among People on Quarantine as a Consequences of COVID-19 Pandemic an Online Cross-sectional Study
}

\author{
Aasim Ur Rehman Ganie ${ }^{1,{ }^{*}}$, Irtifa Mukhter ${ }^{2}$, Rituparna Dey $^{2}$, Mehreena Manzoor $^{3}$
}

Aasim Ur Rehman Ganie ${ }^{1, *}$, Irtifa Mukhter ${ }^{2}$, Rituparna Dey $^{2}$, Mehreena Manzoor ${ }^{3}$ ${ }^{1}$ Research Scholar, Department of Psychiatric Social Work, NIMHANS, Bengaluru, Karnataka INDIA. ${ }^{2}$ Research Scholar, Delhi School of Social Work, University of Delhi, Delhi, INDIA.

${ }^{3}$ Research Scholar, Jawaharlal Nehru University, New Delhi, INDIA.

\section{Correspondence}

Mr. Aasim Ur Rehman Ganie

Research Scholar, Department of

Psychiatric Social Work, NIMHANS,

Bengaluru-560029, Karnataka INDIA.

Mobile no: +919419982856

Email: salvataasim@gmail.com

History

- Submission Date: 18-04-2021;

- Revised Date: 11-05-2021;

- Accepted Date: 20-06-2021;

DOI : 10.5530/ijmedph.2021.3.27

Article Available online

http://www.ijmedph.org/v11/i3

\section{Copyright}

(C) 2021 Phcog.Net. This is an openaccess article distributed under the terms of the Creative Commons Attribution 4.0 International license.

\begin{abstract}
Background: Practising and promoting healthy lifestyle behaviours have been one of the major challenges during the COVID-19 Pandemic due to lockdown measures and mandatory isolation. The changing lifestyle concerns and anxiety and stress due to uncertainty about this pandemic have been considered negative implications of COVID-19. Aim: The current study was undertaken to assess the participants' health promoting lifestyle profile due to the COVID-19 related quarantine and isolation. Methods: A cross-sectional online survey was used to assess the participants' health-related lifestyle profile due to COVID-19 related quarantine measures. Health-Promoting Lifestyle Profile -II and socio-demographic sheet with behaviours and practices questions were used to assess changes in health promoting lifestyle behaviours using online platform. Results: The health promoting lifestyle survey was completed by the ( $\mathrm{n}$ 126) participants. The lowest mean scores on the health promoting lifestyle profile questionnaire were found in the domains of physical activity (mean=17.57), health responsibility (mean=20.17) and management of stress (mean=21.09) during the lockdown whereas the highest scores were found in domains of nutrition (mean=23.67), spiritual growth (mean=25.27), and interpersonal relationships (mean=24.15). A significant reduction in the physical activity was coupled with increase in high calorie intake among the participants. Participants were found to have sustained at least one meaningful relationship during the lockdown and regularly attending educational programs on personal health care. Conclusion: The pandemic has witnessed a downfall in physical activities, sleep patterns and increase in nutrition and stress levels among the participants creating a vulnerability of developing metabolic syndromes and affecting immunity. Suggests need for bringing strategies for promoting healthy lifestyle to prevent the occurrence of such metabolic concerns in future epidemics and pandemics.

Key words: COVID-19, Lifestyle, Sedentary Behaviours, Lockdown, Physical Activity.
\end{abstract}

\section{INTRODUCTION}

Lifestyle can be defined as a way of life; it is a path utilized by individuals, communities, and countries and is shaped in explicit geological, monetary, political, social, and religious content. As per WHO, $60 \%$ of related components to individual wellbeing and quality of life are associated with lifestyle choices. ${ }^{1}$ However, after the outbreak of COVID-19, nations' broad lockdown has prompted lifestyle and day-by-day propensity changes in the populace. This examination has been meant to speak to those changes. Seemingly, remaining at home, while a protected measure, may have unintended negative results and may prompt expanded sedentary practices, for example, investing too much time sitting, lying down, or resting for screening exercises, lessening standard physical movement, and so on. Isolation and quarantine can be significant stressors that can add to far and wide change in the populace's lifestyle patterns. Therefore, it may enhance the manifestations of nervousness, panic attacks, frustrations, anxiety or abrupt increment in craving, a sleeping disorder, and depression have been accounted for during the Covid lockdown. ${ }^{2}$

During the early stages of the pandemic outbreak researchers and scientists have shared information about the potential negative impacts the pandemic may have upon health behaviors of people..$^{3-6}$ These preliminary studies indicate that due to lockdown measures and longer stay-at-home can limit physical activity and promote sedentary behaviour. It has also been found that Obesity and a lack of fitness are emerging as risk factors for developing more severe symptoms and complications if one becomes infected with COVID-19., ${ }^{3,8}$ Regarding lifestyle guidelines and healthy behaviours, various recent reviews have emphasized on the role of maintaining a healthy nutritional status ${ }^{9}$ and engaging in physical exercise at home ${ }^{10}$ in the management of the COVID-19 outbreak. Similar recommendations were made at the time of the influenza pandemic outbreak in
Cite this article : Ganie AUR, Mukhter I, Dey R, Manzoor M. Health Promoting and Lifestyle Behaviour Changes among People on Quarantine as a Consequences of COVID-19 Pandemic an Online Cross-sectional Study. Int J Med Public Health. 2021;11(3):150-4. 
1918 when public health nurses adhered to precepts of good hygiene, nutrition, fresh air, and rest. ${ }^{11}$

To date, numerous environmental health-related lifestyle factors have been extensively studied; however, lifestyle behaviors including dietary changes, restricted physical activity and the effect of increased indoor and screen time remain an under-researched area. ${ }^{12}$ Therefore, to address such gap, the current study focuses on studying the changes in health promoting and lifestyle behaviours during compulsory isolation among people during COVID-19 pandemic. Such studies are necessary step for the design of rational and effective public policies and would provide the much-needed evidence to design interventions to prevent lifestylerelated health changes in any new pandemic.

\section{MATERIALS AND METHODS}

A cross sectional online survey design was decided by the researchers with common in the field to assess the health-related lifestyle profile of the participants due to COVID-19 related lockdown and quarantine measures. The date was collected using an online (anonymous) survey platform (Google Form) as per the Government's guidelines to minimize face-to-face or physical interaction with the participants. The survey was carried out between July 13 to August 30, 2020. The target population was the general Indian population. Inclusion criteria were being (i) a citizen of India, (ii) 18 years or above in age (iii) being able to read and write the English language and (iv) under quarantine or home isolation. The data was collected data anonymously, without collecting identifying information about the participants.

\section{Procedure}

Participants meeting the criteria of (i) a citizen of India, (ii) 18 years or above in age, (iii) being able to read and write the English language, and (iv) under quarantine or home isolation were recruited for the study from various social media platforms (e.g., Facebook, Telegram, WhatsApp), using convenience sampling technique. Data from the participants were collected by using an anonymous online form created on Google Form platform. The online form was shared on social media sites and groups with inclusion criteria clearly mentioned. Once the participant clicked on the link, they were given information about the nature and purpose of survey on the first page. A total of 126 people completed the online survey. Participants were well informed about the procedure and purpose of the study and the confidentiality of their information. Informed consent was taken from each participant online during the study. Furthermore, all data were collected anonymously and analysed by using the SPSS (SPSS for Windows, 22.0 IBM Crop., Armonk, NY, USA).

\section{Data Collection tools}

After reading and signing the informed consent page the participants were taken to next page of the form which contained three parts. The first and second part of the online questionnaire was used to collect the socio-demographic information and information about participants' knowledge, attitude, and practices towards about COVID-19. The third part of the survey was adopted from Health-Promoting Lifestyle Profile -II. ${ }^{13}$ This 52 -item summated behaviour rating scale employs a 4-point response format to measure the frequency of self-reported healthpromoting behaviors in the domains of health responsibility, physical activity, nutrition, spiritual growth, interpersonal relations and stress management. For all questions, scores could range from 1 through 4 .

\section{Instrument details}

Background Information Sheet (Sociodemographic sheet) was used to collect demographic and KAP information related COVID-19. Healthpromoting behaviors and lifestyle practices were assessed using the 52- item, 4-point scale assesses the frequency with which individuals report engaging in activities directed toward increasing their level of health and well-being. Responses are scaled from 1. "Never," to 4,"Routinely." This instrument is composed of six subscales (Physical Activity, Spiritual Growth, Health Responsibility, Interpersonal Relations, Nutrition, and Stress Management) derived from the earlier HPLP, literature review, and expert confirmation. Reliability and validity of the HPLPII have been supported in psychometric testing with a sample of 712 adults. The internal consistency reliability of the HPLP has been consistently high. Internal consistency reliability of the HPLPII total score in this study was .92: subscales ranged from .74 to .86 . Evidence supports the use of the HPLP as a valid measure of health behaviour and lifestyle profile in persons.

\section{RESULTS}

Analyses in this study included all the 126 participants (48.4\% Males and $51.6 \%$ females) between the ages of 18 and 66 who responded to the online questionnaire. All participants had been under quarantine or home isolation during the lockdown period for minimum of 14 days. With Participants were between the ages of 18 and 66 years (mean 26.74, SD 6.724). Among the participants (68.3\%) had post-graduation, (25\%) had graduation and $(6.4 \%)$ of the participants had elementary and secondary level of education. Most of the respondents were unmarried $(82.5 \%)$, and $(16.7 \%)$ of the respondents were married. Majority of the participants reported living in rural or sub-urban settings (56.3\%) overwhelmingly, majority of participants from rural or sub-urban have access to internet and using the social media sites, (43.7\%) living in urban or metropolitan cities. (64.3\%) of the respondents reported being unemployed at the time of survey, (31\%) and (4\%) of the respondents are employed or have started their own business. (74.6\%) of the respondents are currently enrolled with any short or long academic course Table 1.

The overall lifestyle profile of the participants is depicted in the Table 2) which presents mean scores of HPLP-II and the sub-scales of Health Responsibility $(n=126)$ at $(20.17 \pm 05.13)$, Physical Activity (17.57 \pm 04.64), Nutrition (23.67 \pm 04.36), Spiritual Growth (25.27 \pm 05.26$)$, Interpersonal Relationships $24.15 \pm 04.51$, Stress Management (21.09 \pm 04.22) the total mean score of Health Promoting Lifestyle Profile-II is at $(142.46 \pm 26.23)$ with the possible range of scores Health Responsibility (9-36), Physical Activity (8-32), Nutrition (9-36), Spiritual Growth(9-36) Interpersonal Relations (9-36), Stress Management (8-32) and the total profile score of HPLP-II (52-209).

\section{Item Analysis}

On the analysis of individual items of HPLP, participants were asked to rate their profile with the fifty-two statements of HPLP-II. $41 \%$ of the respondents reported that during the lockdown and quarantine period, sometimes they choose a diet which is low in fat, saturated fat, and cholesterol, planned exercise $38.1 \%$, getting routinely enough sleep $42.9 \%$, about $20.6 \%$ of the participants reported that they never had regular exercise during the period, often maintained a meaningful relationship with others $41.3 \%$, routinely looking forward to the plans and life $38.1 \%$, sometimes spending time with friends, $36.5 \%$, respondents who often found it easy to show concern, love, and warmth to others, $42.9 \%$, reported that often they were eating 2-3 servings of milk, yogurt or cheese each day, $29.4 \%$, respondents who never find their needs for intimacy during the lockdown period $23.8 \%$, routinely eat only 2-3 servings from meat, poultry, fish, dried beans, eggs, and nuts group each day $19 \%$, and $48.4 \%$ of the respondents reported that they attended educational programs on personal health care during the lockdown period 


\section{Health Behaviours and Practices}

The COVID-19 related health behaviors and practices are presented in a bar diagram Figure 1, and statements were given which the respondents were supposed to select as per their actions and practices. Among the respondents (13.49\%) (17 responses) reported that they do not follow any preventive behaviours to limit the risk of the coronavirus during the lockdown period. There were (93) responses $(73.8 \%)$ on the statement that participants reported they encourage others to practice the health behaviours during the covid-19 lockdown. Regarding the mandatory health behaviours statements like using face mask while stepping out there were 115 responses (91.2\%), avoiding touching of mouth, eyes and nose with unclean hands (102) responses (80.9\%), maintaining physical distancing (102) responses (80.9\%) and washing of hand regularly (111) responses $(88.9 \%)$. Majority of the respondents were found maintaining the healthy behaviours and practices to limit the risk of the virus. However, it lays scope for more decentralization of information and health education among the masses better to contain the risk of COVID-19 or future viruses.

Table 1: Socio-demographic details of the participants.

\begin{tabular}{|c|c|c|c|}
\hline No. & Variables & $\begin{array}{c}\text { Percentage/ } \\
\text { mean } \pm S D\end{array}$ & Gender \\
\hline \multirow[t]{3}{*}{01} & Age $($ mean $\pm S D)$ & $26.74 \pm 6.72502$ & \\
\hline & Male & $61(48.4 \%)$ & \\
\hline & Female & $65(51.6 \%)$ & \\
\hline \multirow[t]{3}{*}{03} & Domicile & & \\
\hline & Rural & $71(56.3 \%)$ & \\
\hline & Urban & $55(43.7 \%)$ & \\
\hline \multirow[t]{3}{*}{05} & Marital status & & \\
\hline & Married & 104(82.5\%) & \\
\hline & Unmarried & $21(16.7 \%)$ & \\
\hline $\begin{array}{l}\text { Divorced/ } \\
\text { separated }\end{array}$ & $01(0.8 \%)$ & & \\
\hline \multirow[t]{5}{*}{08} & $\begin{array}{l}\text { Employment } \\
\text { status }\end{array}$ & & \\
\hline & Employed & $31(24.6 \%)$ & \\
\hline & Unemployed & $81(64.3 \%)$ & \\
\hline & Self-employed & $05(4.0 \%)$ & \\
\hline & $\begin{array}{l}\text { Others/part-time } \\
\text { etc. }\end{array}$ & $09(7.1 \%)$ & \\
\hline \multirow[t]{5}{*}{09} & $\begin{array}{l}\text { Educational } \\
\text { Level }\end{array}$ & & \\
\hline & Middle & $05(04 \%)$ & \\
\hline & Secondary & $03(2.4 \%)$ & \\
\hline & Graduation & $32(25.4 \%)$ & \\
\hline & Post-Graduation & $86(68.3 \%)$ & \\
\hline \multirow[t]{3}{*}{10} & Profession & & \\
\hline & $\begin{array}{c}\text { Govt/Private/ } \\
\text { Semi-Private Jobs }\end{array}$ & $32(25.4 \%)$ & \\
\hline & Student & $94(74.6 \%)$ & \\
\hline
\end{tabular}

SD: Standard Deviation.

\section{DISCUSSION}

The present article aimed to assess the health-promoting lifestyle profile of persons quarantined during the COVID-19 pandemic and the Government lockdown to limit the virus's risk. Given the concerns about the increasing spread of COVID-19, people must follow infection control and safety precautions. Homestay is a fundamental safety step that can limit infections from spreading widely. But prolonged home stays can increase behaviors that lead to inactivity and contribute to anxiety and depression, which in turn can lead to a sedentary lifestyle known to result in a range of chronic health conditions. Nutritional habits will change due to reduced availability of goods, limited access to food caused by restricted store opening hours, and a switch to unhealthy food. Emerging evidence suggests that the Coronavirus pandemic has initiated a devastating threat to our public health, lifestyles, and countries' economies. As a consequence of observing quarantine and lockdown measures, physical inactivity brought about by immobilization could downgrade organs' capacity to remain fully functional and operationally efficient. This means our organs' vulnerability could become compromised and unable to resist and fight the likelihood of viral infections. ${ }^{14}$

The lifestyle patterns may be changed also due to the containment measures, the consequent risk of sedentary behaviors, and modification in smoking and sleeping habits. The participants were also found getting involved in sedentary behaviours, consumptions of high sugars, fatty

\section{Table 2: Level of Health Promoting Lifestyle Profile-II and the sub-} scales.

\begin{tabular}{|cccccc} 
No & $\begin{array}{c}\text { Scale /Sub- } \\
\text { scale }\end{array}$ & Minimum & Maximum & Mean & $\begin{array}{c}\text { Standard } \\
\text { Deviation }\end{array}$ \\
\hline 1 & $\begin{array}{c}\text { HPLP-II } \\
(n=126)\end{array}$ & 69.00 & 228.00 & 142.46 & 26.23 \\
2 & $\begin{array}{c}\text { Health } \\
\text { Responsibility } \\
3\end{array}$ & 10.00 & 35.00 & 20.17 & 05.13 \\
& $\begin{array}{c}\text { Physical } \\
\text { Activity }\end{array}$ & 09.00 & 28.00 & 17.57 & 04.64 \\
4 & Nutrition & 14.00 & 36.00 & 23.67 & 04.36 \\
5 & $\begin{array}{c}\text { Spiritual } \\
\text { Growth }\end{array}$ & 10.00 & 36.00 & 25.27 & 05.26 \\
6 & $\begin{array}{c}\text { Interpersonal } \\
\text { Relationships }\end{array}$ & 11.00 & 36.00 & 24.15 & 04.51 \\
7 & $\begin{array}{c}\text { Stress } \\
\text { Management }\end{array}$ & 08.00 & 32.00 & 21.09 & 04.22 \\
\hline
\end{tabular}

HPLP-II: Health Promoting Lifestyle Profile-II

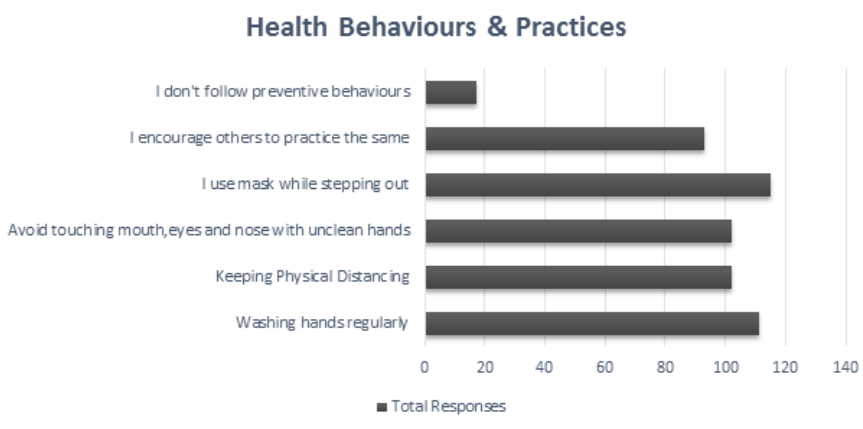

Figure 1: Health Behaviours and Practices 
products, and decreased physical activities which can be attributed to psychological distress, boredom or restricted outdoor movements. In addition to that about $47 \%$ of the respondents had been found have some issues with related to their sleep during the lockdown or quarantined period. This is inconsistent with the findings of studies which reported an association between sleep disturbances and obesity due to increasing the secretion of pro-inflammatory cytokines by the increased visceral adipose could contribute to altering the sleep-wake rhythm. ${ }^{15,16}$ The interruption of the work routine caused by the quarantine also resulted in boredom, which is associated with a greater energy intake. In addition to boredom, hearing or reading continuously about the COVID-19 from media can be stressful. In the current study the participants had been found involved in eating 2-3 servings of milk, yogurt or cheese each day, routinely eating only 2-3 servings from meat, poultry, fish, dried beans, eggs, and nuts group each day having higher intake of carbohydrates, proteins and fat. This increase in consumptions of nutrition can be attributed to the stress which leads subjects toward overeating, especially 'comfort foods' rich in sugar, defined as "food craving". ${ }^{17-19}$

There is no doubt that the COVID-19 pandemic adversely affected people's physical and other health-related behaviors. However, during the lockdown period, the Government of India prohibited the great majority of outdoor and social activities (e.g., going to the gym, parties, social gatherings, etc.), resulting in reduced physical activity. Maintaining regular physical activity and routinely exercising in a safe home environment is an essential strategy for healthy living during the coronavirus crisis. There is a close relationship between well-being and the higher healthy behaviours. The survey also found that respondents were able to attend educational programs on personal health. Most of them often maintained a meaningful relationship with others. It was found also that participants found it easy to show concern, love, and warmth to others. Creating and maintaining positive well-being may act as a modifiable protective factor that could reduce Cardiovascular diseases' burden through its potential influences on lifestyle behaviors. Studies have found that People with higher positive well-being tend to have better health behaviors, including non-smoking, greater physical activity, better dietary patterns, and lower sleep disturbances. ${ }^{20,21}$ The outbreak of COVID-19 pandemic has changed how we work, learn and interact as social distancing guidelines have led to a more virtual existence, both personally and professionally. It has also brought pressing need to provide individuals, communities, and health agencies with information to help maintain healthy lifestyles to some degree while in isolation. The future research should be focus on carrying prospective studies to understand better the long-lasting effects of COVID-19 on lifestyle and sedentary behaviors and their changes with representative samples.

\section{Limitations}

The current study although presents first online based findings on health promoting and lifestyle behaviours during COVID-19 pandemic in Indian context, the authors acknowledge some limitations. Sections of a target population which may not have access to internet, feedback from such individuals could have been very effective for the current study. The study used convenient sampling, which limits generalisability of results. Finally, the online form was in English language, designing of the same in other languages could have generated more participation.

\section{CONCLUSION}

The world population is experiencing life-changing challenges due to the outbreak of COVID-19 pandemic. The COVID-19 pandemic has placed the population at a double risk because physical inactivity and increased sedentary behaviours negatively impact individuals' overall well-being and may exacerbate non-communicable disease threats (e.g., obesity, hypertension, higher cholesterol levels and diabetes). The restrictions due to the pandemic may lead to unforeseen mental health issues and can cause shifts in our sleep patterns, physical activity, and eating habits which are pillars of our immune system. Thus, the changes in lifestyles and increasing sedentary behaviours among the populations should be matter of concern for the government agencies, policy makers and other stakeholders must bring strategies for the healthy lifestyle and behaviours to prevent the occurrence of these concern in future epidemics and pandemics.

\section{ACKNOWLEDGEMENT}

Authors would like to thanks the anonymous referees for their useful suggestion. Authors would also like to thanks Mr. Gowhar Ahmad Shalla, Ms. Insha Mushtaq and Ms. Seerat Mukhter for their valuable inputs in designing the google form and their support during data collection phase.

\section{CONFLICT OF INTEREST}

The authors declared no potential conflicts of interest with respect to the research, authorship, and/or publication of this article.

\section{ABBREVIATIONS}

SD: Standard Deviation; HPLP: Health Promoting Lifestyle Profile; SES: Socio-Economic Status; COVID-19: Coronavirus Disease-2019; NY: New York; USA: United States of America.

\section{REFERENCES}

1. Ziglio E, Currie C, Rasmussen VB. The WHO cross-national study of health behaviour in school aged children from 35 countries: Findings from 2001-2002. Journal of School Health. 2004;74(6):204-6.

2. Huang Y, Zhao N. Generalized anxiety disorder, depressive symptoms and sleep quality during COVID-19 outbreak in China: A web-based cross-sectional survey. Psychiatry Research. 2020; 288:112954.

3. Carter SJ, Baranauskas MN, Fly AD. Considerations for obesity, vitamin D, and physical activity amid the COVID-19 pandemic. Obesity. 2020;28(7):1176-7.

4. Hammami A, Harrabi B, Mohr M, Krustrup P. Physical activity and coronavirus disease 2019 (COVID-19): Specific recommendations for home-based physical training. Managing Sport and Leisure. 2020;1-6.

5. Jiménez-Pavón D, Carbonell-Baeza A, Lavie CJ. Physical exercise as therapy to fight against the mental and physical consequences of COVID-19 quarantine: Special focus in older people. Progress in Cardiovascular Diseases. 2020;63(3):386-8.

6. Mattioli AV, Puviani MB, Nasi M, Farinetti A. COVID-19 pandemic: The effects of quarantine on cardiovascular risk. European Journal of Clinical Nutrition. 2020;74(6):852-5.

7. Dietz W, Santos-Burgoa C. Obesity and its implications for COVID-19 mortality. Obesity. 2020;28(6):1775-6.

8. Lighter J, Phillips M, Hochman S, Sterling S, Johnson D, Francois F, et al. Obesity in patients younger than 60 years is a risk factor for Covid-19 hospital admission. Clinical Infectious Diseases. 2020;71(15):896-7.

9. Zhang L, Liu Y. Potential interventions for novel coronavirus in China: A systematic review. Journal of Medical Virology. 2020;92(5):479-90.

10. Lippi G, Henry BM, Sanchis-Gomar F. Physical inactivity and cardiovascular disease at the time of coronavirus disease 2019 (COVID-19). European Journal of Preventive Cardiology. 2020;27(9):906-8.

11. Vessey JA, Betz CL. Everything old is new again: COVID-19 and public health Journal of Pediatric Nursing. 2020;52:A7.

12. Chen $P$, Mao L, Nassis GP, Harmer P, Ainsworth BE, Li F. Coronavirus disease (COVID-19): The need to maintain regular physical activity while taking precautions. J Sport Health Sci. 2020;9(2):103-4.

13. Walker SN, Sechrist KR, Pender NJ. The health-promoting lifestyle profile: Development and psychometric characteristics. Nursing Research. 1987,36(2):7681.

14. Ugbolue UC, Duclos M, Urzeala C, Berthon M, Kulik K, Bota A, et al. An Assessment of the Novel COVISTRESS Questionnaire: COVID-19 Impact on Physical Activity, Sedentary Action and Psychological Emotion. Journal of Clinical Medicine. 2020;9(10):3352

15. Muscogiuri G, Barrea L, Annunziata G, Somma DC, Laudisio D, Colao A, et al. Obesity and sleep disturbance: The chicken or the egg?. Critical Reviews in 
Food Science and Nutrition. 2019;59(13):2158-65.

16. Pugliese G, Barrea L, Laudisio D, Salzano C, Aprano S, Colao A, et al. Sleep apnea, obesity, and disturbed glucose homeostasis: Epidemiologic evidence, biologic insights, and therapeutic strategies. Current Obesity Reports. 2020:9(1):30-8.

17. Moynihan AB, Tilburg VWA, Igou ER, Wisman A, Donnelly AE, Mulcaire JB. Eaten up by boredom: Consuming food to escape awareness of the bored self. Frontiers in Psychology. 2015;6:369.

18. Yılmaz C, Gökmen V. Neuroactive compounds in foods: Occurrence, mechanism and potential health effects. Food Research International. 2020;128:108744.

19. Rodríguez-Martín BC, Meule A. Food craving: New contributions on its assessment, moderators, and consequences. Frontiers in Psychology. 2015;6:21.

20. Sin NL. The protective role of positive well-being in cardiovascular disease: Review of current evidence, mechanisms, and clinical implications. Current Cardiology Reports. 2016;18(11):1-0.

21. Boehm JK, Kubzansky LD. The heart's content: The association between positive psychological well-being and cardiovascular health. Psychological Bulletin. 2012 138(4):655-91.

Cite this article : Ganie AUR, Mukhter I, Dey R, Manzoor M. Health Promoting and Lifestyle Behaviour Changes among People on Quarantine as a Consequences of COVID-19 Pandemic an Online Cross-sectional Study. Int J Med Public Health. 2021;11(3):150-4. 